\title{
Nucleation and growth of a multicomponent metallic glass ${ }^{\circledR}$
}

\author{
ARUN PRATAP*, K G RAVAL ${ }^{\dagger}$, AJAY GUPTA ${ }^{\ddagger}$ and S K KULKARNI ${ }^{\#}$ \\ Applied Physics Department, Faculty of Technology and Engineering, M S University of Baroda, Baroda 390 001, India \\ ${ }^{\dagger}$ Electronics Department, Narmada College of Science and Commerce, Zadeshwar, Bharuch 392 011, India \\ ${ }^{\ddagger}$ Inter University Consortium for DAE Facilities, Khandwa Road, Indore 452 001, India \\ \#Department of Physics, University of Pune, Pune 411 007, India
}

\begin{abstract}
The metallic glass samples of $\mathrm{Fe}_{67} \mathrm{Co}_{18} \mathrm{~B}_{14} \mathrm{Si}_{1}(2605 \mathrm{CO})$, prepared by the melt spinning technique were procured from the Allied Corporation. The kinetics of crystallization of this multicomponent glassy alloy is studied using differential scanning calorimetry (DSC). The crystallization data have been examined in terms of modified Kissinger and Matusita equations for the non-isothermal crystallization. The results show enhanced bulk nucleation in general. At high heating rates added to it is surface induced abnormal grain growth resulting in fractal dimensionality.
\end{abstract}

Keywords. Activation energy; isothermal annealing; abnormal grain growth; fractal dimensionality.

\section{Introduction}

Metallic glasses are well known for their superior magnetic properties, improved mechanical strength and excellent corrosion resistance (Karve and Kulkarni 1985). The industrial importance of iron-silicon alloys, especially in the form of transformer sheet with a controlled preferred orientation texture, has led to a large number of investigations of its abnormal grain growth characteristics (Detert 1959; Walter 1965).

Thermal analysis has been extensively used for studying the kinetics of chemical reaction (Piloyan et al 1966; Tanabe and Otsuka 1977) and crystallization of glasses (Thakur and Thiagrajan 1966, 1968; Matusita et al 1975; Matusita and Sakka 1979; Pratap et al 1995). It was shown that determination of mechanism of crystallization is extremely important to determine the activation energy of crystal growth from DSC data.

The purpose of present study is to apply DSC to ascertain the mechanism of crystallization and separate the activation energy of crystallization into those required for nucleation and growth, respectively for the metallic glass $\mathrm{Fe}_{67} \mathrm{Co}_{18} \mathrm{~B}_{14} \mathrm{Si}_{1}(2605 \mathrm{CO})$.

\section{Experimental}

The metallic glass samples of $\mathrm{Fe}_{67} \mathrm{Co}_{18} \mathrm{~B}_{14} \mathrm{Si}_{1}$ (2605CO) were procured from Allied Corporation, USA. They were in the form of continuous ribbon $(2.5 \mathrm{~cm}$ wide and $\sim 40 \mu \mathrm{m}$ thick). The samples were prepared by the melt spinning technique.

\footnotetext{
*Author for correspondence

${ }^{\circledR}$ Paper presented at the 5th IUMRS ICA98, October 1998, Bangalore
}

The crystallization kinetics of this glassy alloy is studied using DSC 2910 (TA Instruments Inc., USA) system. Firstly, the samples were heated with various heating rates to study non-isothermal kinetics. Then, isothermal annealing was performed at a chosen temperature for various time intervals to separate nucleation from growth.

\section{Results and discussion}

Figure 1 shows a typical DSC thermogram of $\mathrm{Fe}_{67} \mathrm{Co}_{18} \mathrm{~B}_{14} \mathrm{Si}_{1}$ glass at a heating rate of $1{ }^{\circ} \mathrm{C} / \mathrm{min}$. Two exothermic processes occur in the heat flow curve of the as-received sample. The low temperature process exhibits the appearance of crystallites of $\alpha$-Fe structure (bcc) located in the amorphous matrix. When the temperature is raised to $740^{\circ} \mathrm{K}$, the $\alpha$-phase increases and new phases $\mathrm{Fe}_{3} \mathrm{~B}$ and $\mathrm{Co}_{2} \mathrm{~B}$ appear while the amorphous phase almost disappears. Our results are consistent with the investigations of structural changes in the process of crystallization of $\mathrm{Fe}_{66} \mathrm{Co}_{12} \mathrm{Si}_{9} \mathrm{~B}_{13}$ glass using measurement of positron lifetime (Filipecki et al 1995).

The experimental data on crystallization has been interpreted on the basis of the method of modified Kissinger's equation (Kissinger 1957; Matusita and Sakka 1980) for determination of activation energy and fractional crystallization method (Matusita and Sakka 1979) for ascertaining mechanism.

From the equation suggested (Matusita and Sakka 1979) for non-isothermal crystallization, the activation energy for crystallization, $E_{\mathrm{c}}$ can be evaluated as

$$
\ln [-\ln (1-x)]=-n \ln (\alpha)-1.052 m E_{\mathrm{c}} / R T+\text { const., }
$$

where $x$ is the fractional crystallization, at any temperature $T$, heated at uniform rate. 
For the evaluation of the order parameter $n, \ln [-\ln (1-$ $x)$ ] was plotted as a function of $\ln (\alpha)$ (figure 2 ). The average value derived from the plots at various temperatures comes out to be 3.809 for the first crystallization peak and its value derived for the second peak is $5 \cdot 44$. Normally, $n$ should not exceed 4 (i.e. the value for three-dimensional bulk nucleation). In the present case, it is assumed that the surface induced abnormal grain growth expected for $\mathrm{Fe}$ based alloys (Cahn 1970) is responsible for the high value of $n$ for this multicomponent glass for second stage crystallization. Similar high values of $n$ (i.e. $n=6$ ) has been reported for a ternary chalcogenide glass (Mahadevan et al 1986). Since no particular heat treatment was given to nucleate the samples before thermal analysis, the dimensionality of growth $m$ is taken to be equal to $(n-1)$. In the present case, the evaluated value of $n$ is not an integer. This means that crystallization occurs with fractal dimensionality and the dimensionality of growth $m=$ $(n-1)=2.809$ for the first crystallization peak and $m=4.44$

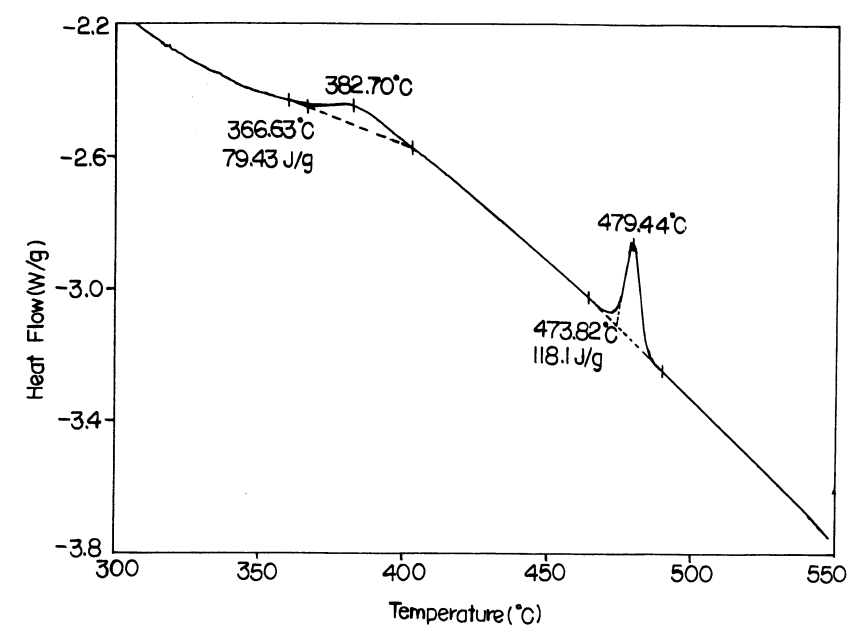

Figure 1. Thermogram at a heating rate of $1^{\circ} \mathrm{C} / \mathrm{min}$.

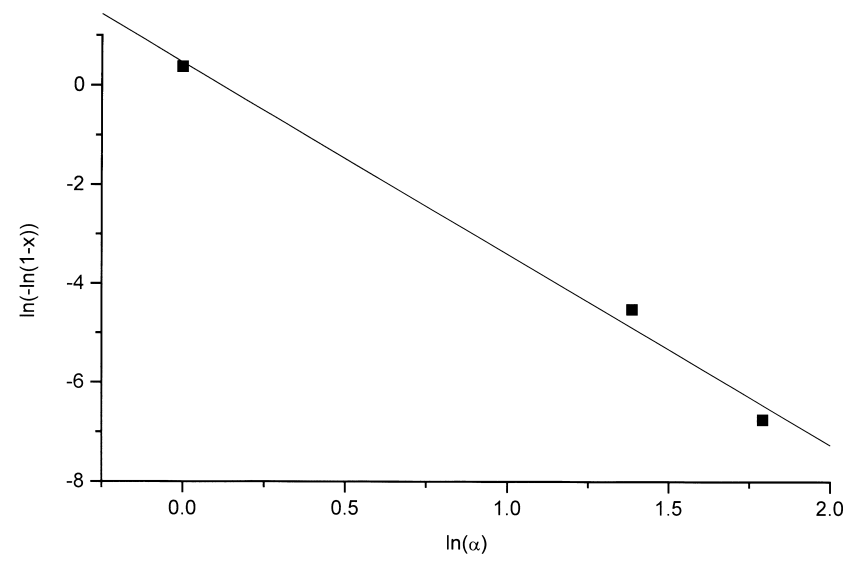

Figure 2. $\ln [-\ln (1-x)]$ vs $\ln \alpha$ for the first crystallization peak. for the second peak. Fractal dimensionality of the order of 4 in the case of surface scattering from particles of colloidal aggregated of silica using X-rays is already reported (Schaefer and Keefer 1984). Recently, growth dynamics of fractal Ge clusters during crystallization of amorphous phase on polycrystalline Au layer has been observed (Kikukawa 1994).

For the evaluation of activation energy of crystallization $E_{\mathrm{c}}$, the modified Kissinger equation (Matusita and Sakka 1980) is used and is given by the following expression

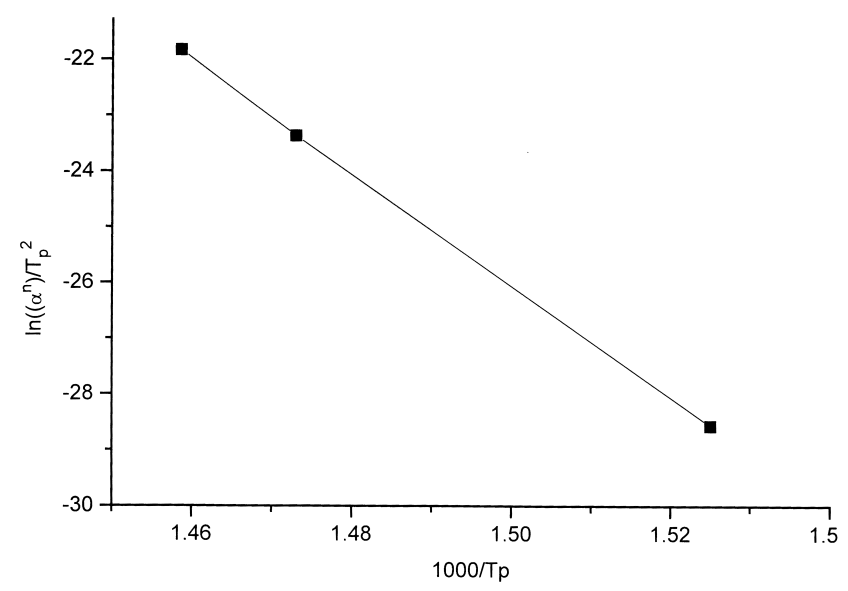

Figure 3. $\ln \left(\alpha^{n} / T_{\mathrm{p}}^{2}\right)$ vs $\left(1 / T_{\mathrm{p}}\right)$ for the first peak.

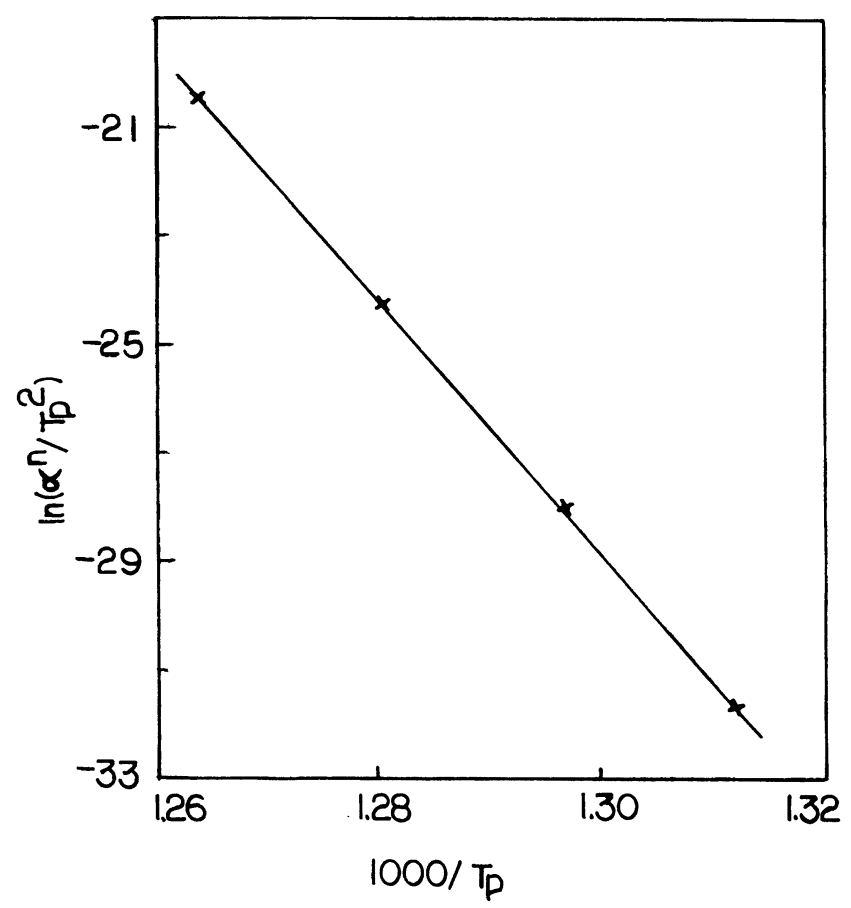

Figure 4. $\ln \left(\alpha^{n} / T_{\mathrm{p}}^{2}\right)$ vs $\left(1 / T_{\mathrm{p}}\right)$ for the second crystallization peak. 


$$
\ln \left(\alpha^{n} / T_{\mathrm{p}}^{2}\right)=-m E_{\mathrm{c}} / R T_{\mathrm{p}}+\ln K,
$$

where the shift in peak crystallization temperature $T_{\mathrm{p}}$ with heating rate $\alpha$ is used to determine $E_{\mathrm{c}}$ and $m$ is dimensionality of growth. Using the value of the order parameter $n=3.809$ and the dimensionality of growth $m=2.809$ for the first crystallization event and the corresponding values of $n=5.44$ and $m=4.44$ for the second peak of crystallization, $E_{\mathrm{c}}$ is computed from the slope of $\ln \left(\alpha^{n} / T_{\mathrm{p}}^{2}\right)$ versus

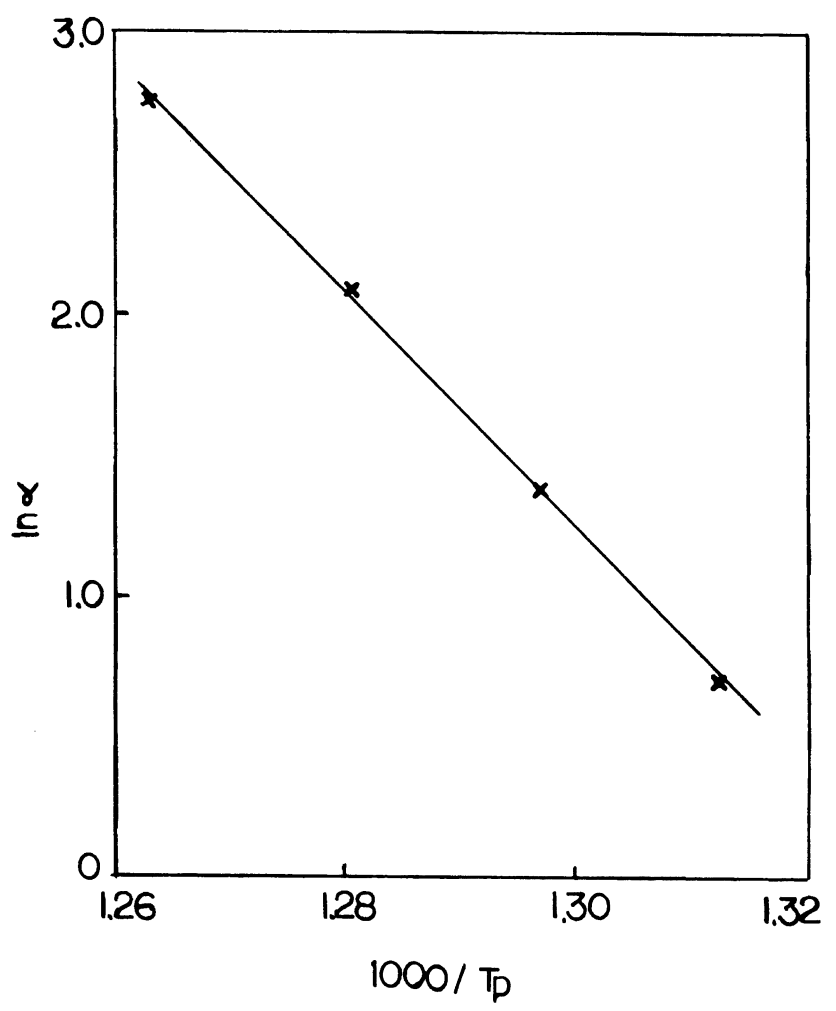

Figure 5. $\ln \alpha$ as a function of $\left(1 / T_{\mathrm{p}}\right)$ for second peak.

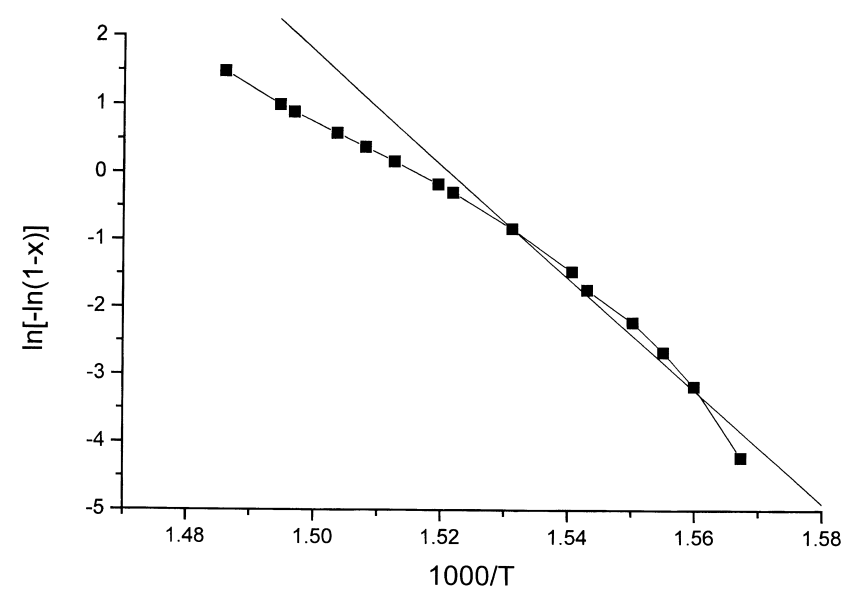

Figure 6. $\ln [-\ln (1-x)]$ at various temperatures for the first peak at a typical heating rate of $1^{\circ} \mathrm{C} / \mathrm{min}$. $\left(1 / T_{\mathrm{p}}\right)$. These plots are shown in figures 3 and 4 for the first and second crystallization peaks respectively. The corresponding values of $E_{\mathrm{c}}$ derived from the first and second peaks using (2) from figures 3 and 4 come out to be $299.15 \mathrm{KJ} / \mathrm{mol}$ and $440.4 \mathrm{KJ} / \mathrm{mol}$. The reported values (Baro et al 1991) for the two-step recrystallization of a glass of very close composition $\left(\mathrm{Fe}_{65} \mathrm{Co}_{18} \mathrm{~B}_{16} \mathrm{Si}_{1}\right)$ are $260.06 \mathrm{KJ} / \mathrm{mol}$ and $394.9 \mathrm{KJ} / \mathrm{mol}$ for the first and second step, respectively for amorphous sample. The closeness of the activation energy values shows the similarity of recrystallization of the two systems. The higher values of $E_{\mathrm{c}}$ for the second step shows that first stage crystallization is easier as compared to second step.

An alternate approach is also applied to infer $(m / n) E_{\mathrm{c}}$ from the slope of the $\ln \alpha$ vs $\left(1 / T_{\mathrm{p}}\right)$ plot itself. Figure 5 shows the ln $\alpha$ vs $1 / T_{\mathrm{p}}$ data for the second peak. The value of $E_{\mathrm{c}}$ for second stage crystallization evaluated knowing $m$ and $n$ is $433.3 \mathrm{KJ} / \mathrm{mol}$ which lies quite close to the value derived from modified Kissinger equation (i.e. 440.4 KJ/mol).

From the slope of the $\ln [-\ln (1-x)]$ vs $\left(1 / T_{\mathrm{p}}\right)$ data (figures 6 and 7), $m E_{\mathrm{c}}$ was calculated using (1). $m E_{\mathrm{c}}$ was observed to be heating rate dependent. For the first stage

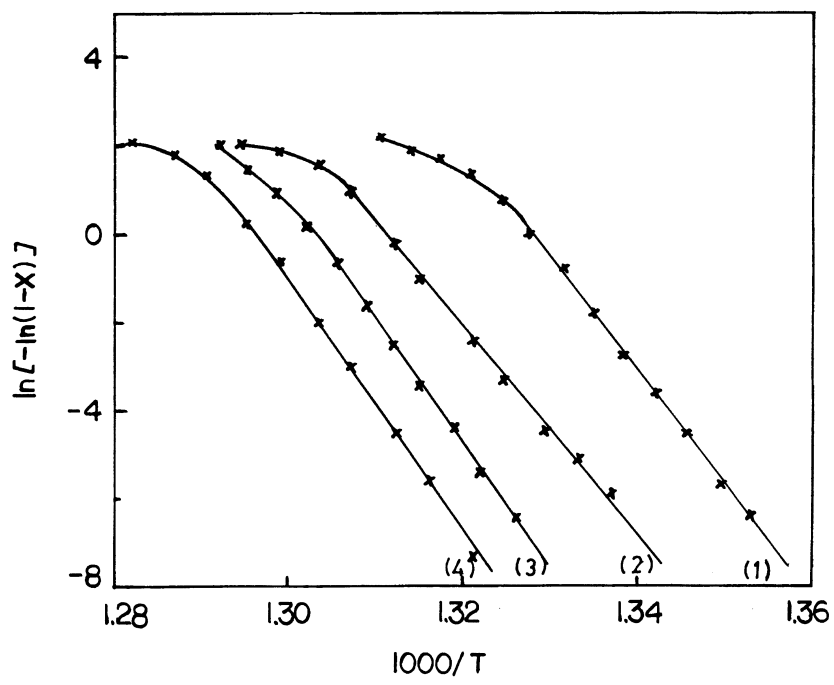

Figure 7. $\ln [-\ln (1-x)]$ at various temperatures for the second peak at various heating rates in degree/min indicated in the parentheses with various curves.

Table 1. Heating rate dependence of dimensionality.

\begin{tabular}{lcc}
\hline \multicolumn{3}{c}{ From $\ln [-\ln (1-x)]$ vs $1 / T$ data } \\
\hline $\begin{array}{l}\text { Heating } \\
\text { rate }\end{array}$ & $\begin{array}{c}1.052 m E_{\mathrm{c}} \\
(\mathrm{KJ} / \mathrm{mol})\end{array}$ & $m$ \\
\hline $1^{\circ} \mathrm{C} / \mathrm{min}$ & $2144 \cdot 5$ & 4.63 \\
$2^{\circ} \mathrm{C} / \mathrm{min}$ & $1955 \cdot 3$ & 4.22 \\
$3^{\circ} \mathrm{C} / \mathrm{min}$ & $2292 \cdot 4$ & 4.95 \\
$4^{\circ} \mathrm{C} / \mathrm{min}$ & $2462 \cdot 2$ & $5 \cdot 31$ \\
\hline
\end{tabular}




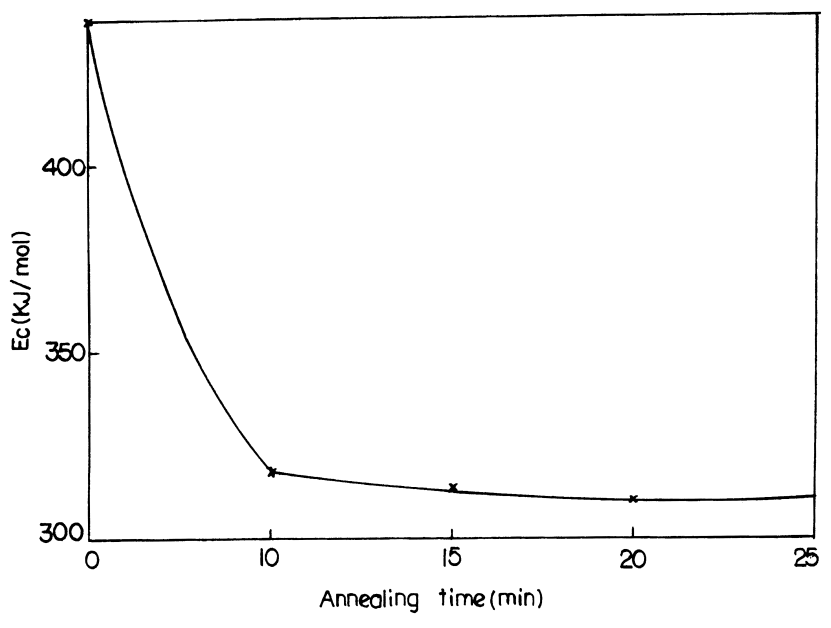

Figure 8. $E_{\mathrm{c}}$ vs annealing time for the second crystallization peak.

with the help of $E_{\mathrm{c}}$ value obtained through (2), the various $m$ values corresponding to different heating rates are derived. For the first stage the $m$ values for the plot at a heating rate of $1^{\circ} \mathrm{C} / \mathrm{min}$ and $2^{\circ} \mathrm{C} / \mathrm{min}$ come out to be 2.33 and $2 \cdot 22$, respectively. The decreasing trend of $m$ with heating rate for the first peak shows decreasing dimensionality of nucleation with increasing heating rate. At low heating rate, the particles grow with higher dimensionality. The $m$ values for the second peak are listed in table 1 . Initially $m$ value decreases with increasing rate, but on increasing $m$ further, value trend of $m$ goes from 4.22 to 5.31 showing enhanced surface induced abnormal grain growth at high heating rates. The gradual increase of surface crystallization with increasing heating rate is already reported (Matusita et al 1975).

In order to obtain activation energy of growth, $E_{\mathrm{g}}$ from the second crystallization peak, the samples were annealed at $470^{\circ} \mathrm{C}$ (temperature just before the major crystallization event) for different time intervals (i.e. 10, 15,20 , and $25 \mathrm{~min}$ ). It has been found that the peak temperature, $T_{\mathrm{p}}$ decreases with pre-annealed time. The apparent activation energy calculated by modified Kissinger method for samples annealed for various times are plotted against pre-annealed time (figure 8) and tends to decrease with pre-annealed time reaching a minimum value recognized as $E_{\mathrm{g}}$, which comes out to be $310 \mathrm{KJ} / \mathrm{mol}$. Then, the activation energy of nucleation is deduced from the suggested (Vogel and Von Heimandahl 1983; Lu and Wang 1988) expression

$$
E_{\mathrm{c}}=\frac{a E_{\mathrm{n}}-r b E_{\mathrm{g}}}{a+r b},
$$

where $r=1$ for linear growth, $r=1 / 2$ for parabolic growth, $b=1,2,3$ for one-, two-, three-dimensional growth, respectively. $a=0$ for no nucleation and $a=1$ for constant nucleation. For the present system $r=1 / 2, a=1$ and $b=4.44$ (fractal dimensionality) has been taken. From these values and experimentally determined values of $E_{\mathrm{c}}$ and $E_{\mathrm{g}}$ and using (3), the value of $E_{\mathrm{n}}$ is found to be $729.88 \mathrm{KJ} / \mathrm{mol}$.

\section{Conclusion}

The non-isothermal kinetics using the Matusita and Sakka method provides consistent crystallization curves and important information regarding the mechanism of nucleation and growth. The present Fe-based multicomponent amorphous alloy seems to nucleate with fractal dimensionality owing to abnormal grain growth expected in this system.

\section{Acknowledgements}

The authors are grateful to Dr A M Awasthi, Scientist, IUC for DAE facilities at Indore for providing the DSC equipment for carrying out the present work and to $\mathrm{Mr}$ Suresh Bhardwaj for very patiently taking the thermograms.

\section{References}

Baro M D, Surinach S, Diego J A, Clavaguera-Mora M T and Clavaguera N 1991 Mater. Sci. \& Engg. A133 807

Cahn R W (ed.) 1970 Physical metallurgy (Amsterdam: North Holland)

Detert K 1959 Acta Met. 7589

Filipecki J, Jakubczyk E and Mandecki Z 1995 Nanostructured and non-crystalline materials (ed.) $\mathrm{M}$ Vazquez and $\mathrm{A}$ Hernando (Singapore: World Scientific) p. 369

Karve P P and Kulkarni S K 1985 Corrosion Sci. 251091

Kikukawa T 1994 Mater. Sci. \& Engg. A181/A182 355

Kissinger H E 1957 Anal. Chem. 291702

Lu K and Wang J J 1988 J. Mater. Sci. 233001

Mahadevan S, Giridhar A and Singh A K 1986 J. Non-cryst. Solids $\mathbf{8 8} 11$

Matusita K and Sakka S 1979 Phys. Chem. Glasses 2081

Matusita K and Sakka S 1980 J. Non-Cryst. Solids 38 \& 39741

Matusita K, Sakka S and Matsui Y 1975 J. Mater. Sci. 10961

Piloyan G O, Ryabchikov I D and Novikova O S 1966 Nature 2121229

Pratap A, Prasad A, Joshi S R, Saxena N S, Saksena M P and Amiya K 1995 Mater. Sci. Forum 179-181 851

Schaefer D W and Keefer K D 1984 Phys. Rev. Lett. 531383

Tanabe S and Otsuka R 1977 Netsu 4139

Thakur R L and Thiagrajan S 1966 Bull. Cent. Glass Ceram. Res. Inst. 1333

Thakur R L and Thiagrajan S 1968 Bull. Cent. Glass Ceram. Res. Inst. 1567

Vogel H and Von Heimendahl M 1983 Mater. Sci. Engg. 57171

Walter J L 1965 J. Appl. Phys. 361213 